\title{
Electrification of the Passenger Car Fleet and Its Effect on Resource Use-A Statistical Entropy Analysis Perspective $^{\dagger}$
}

\author{
Alexej Parchomenko ${ }^{1,2}$, Dirk Nelen ${ }^{1}$, Jeroen Gillabel ${ }^{1}$, Karl Vrancken ${ }^{1,3}$ and Helmut Rechberger ${ }^{2}$ \\ 1 VITO, 200 Boeretang, Mol, Belgium \\ 2 TU Wien, Institute for Water Quality and Resource Management, Karlsplatz 13/226, Vienna, Austria \\ 3 Department Bio-engineering, University of Antwerp, Groenenborgerlaan 171, Antwerpen, Belgium \\ † Presented at the Entropy 2021: The Scientific Tool of the 21st Century, 5-7 May 2021; Available online: \\ https://sciforum.net/conference/Entropy2021/.
}

Published: 5 May 2021

The European automotive sector undergoes a severe transformation that is driven by the increasing uptake of alternative drivetrains. In the year 2050 it is expected that $40-80 \%$ of new vehicles entering the vehicle stock will be electric (Hill and Bates, 2018). Even though the electrification of the vehicle stock may contribute positively to reaching the EU climate targets, the transformation will also create costs, not only monetary, but also in terms of efforts and losses of functionality. On the one hand substantial efforts will be needed to extract, concentrate and refine materials to produce components and vehicles with new drivetrain technology. On the other hand considerable efforts will be related to restoring functionality losses that result from the large-scale exchange of the vehicle fleet. To assess the effect of the vehicle stock transformation on resource use a dynamic material flow analysis (MFA) is employed and five possible future scenarios of the mobility transition are modelled for the EU until 2050. In a second step the results of the MFA are evaluated through the method of Statistical Entropy Analysis (SEA). The SEA results show that the changes in the vehicle stock, its renewal rate, as well as the adaptation of the reuse, remanufacturing-, and recycling- system, need to be aligned to the pace of the transition to minimize the loss of functionality and reduce the efforts involved. The study demonstrates how SEA can be used to evaluate future socio-technological transitions of larger systems like the European automotive system and identify the best combinations of resource management strategies. It is shown that SEA provides insights that allow to quantify hotspots of functionality loss and determine the most effective combinations of product stock and materials management interventions, contributing to more sustainable use of resources and existing stocks.

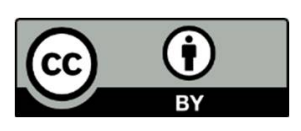

(C) 2021 by the authors. Licensee MDPI, Basel, Switzerland. This article is an open access article distributed under the terms and conditions of the Creative Commons Attribution (CC BY) license (http://creativecommons.org/licenses/by/4.0/). 